\title{
The Relationship between Energy Consumption Growths and Economic Growth in China
}

\author{
Qiang Hou \\ School of Management, Shenyang University of Technology \\ Shenyang 110023, China \\ E-mail: houqiang80@126.com
}

This project is funded by the Education Department of Liaoning Province which No is 2008Z168and doctoral initiating project of Shenyang university of technology.

\begin{abstract}
Energy plays an important role in the economic development. Hence many studies have attempted to test for causality between energy and economic growth. This paper investigates the causal relationship between energy consumption and economic growth in China. By applying techniques of ADF, co-integration, Hsiao's Granger causality, the paper analyzes this relationship, and the results infer that economic growth granger causes energy consumption and energy consumption granger causes economic growth respectively.
\end{abstract}

Keywords: Causality, Energy, GDP, Co-integration, Hsiao's Causality Tests

\section{Introduction}

Energy plays an essential role in an economy, so the relationship between energy consumption and economic growth is now well researched in the literature. Lots of literatures are based on the questions that whether economic growth leads to energy consumption or that energy consumption is the engine of economic growth. The answer to this question has important implication for the policy makers. Empirically it has been tried to find the direction of causality between energy consumption and economic activities for some countries employing the Granger Test, ECM and other techniques. The result show the answer is mixed.

In the recent papers, Morimoto \& Hope (2004) analyzed the relations between electricity and GDP growth in Sri Lanka from 1960 to 1998 by using Granger Test. Ghali and El-Sakka (2004) found that the short-run dynamics of variables indicated that Granger's causality is running in two directions between output growth and energy consumption based on data from Canada. Ghosh (2002) found no co-integration and argued that there is unidirectional Granger causality from economic growth to electricity consumption using annual data covering the time span 1950-1997 in India. Oh and Lee (2004) found causal relationship between energy consumption and economic growth respectively in Korea from 1970 to 1999 using year data by co-integration \& ECM. Paul \& Bhattacharya (2004) investigated the causality between energy consumption and economic growth for India, found different result by using different method. Altinay and Karagol (2005) found that electricity-GDP causality in Turkey from 1950 to 2000 by the method of Doladoand and Granger. Lee (2005) investigated the causality between energy consumption and economic growth for 18 developing countries by using Panel Co-integration and ECM, finding energy-GDP causality exist from 1975 to 2001. Jaruwan Chontanawat (2006) reviewed the papers and listed the mainly research on the relation between energy consumption and economic growth by table from 1985 to 2005 . In these papers, only two ones directly associated with China.

A similar study would be beneficial in China to design an economic policy framework for the energy. The paper tries to research on this question. The reminder paper is organized as follows. Section 2 presents the method used in this paper. Section 3 presents the data and discusses the results of the co-integration analysis. The final section summaries and concludes.

\section{Methodology}

From the literature we can find that there are mainly four methods in this area, including ECM, Ganger, Co-integration and Hsiao's Granger. Each has its advantage and shortcoming. However in four methods, the Hsiao's Granger is later, which enhances Granger-causality by using the Akaike (1969) Final Prediction Error (FPE) criteria to decide lag length, and widely used recently. Given the hypothesis of econometric and the limitation of four methods, lots of literatures adopt three stage methods. This paper also adopts this method.

This method includes the following three stages:

Stage 1: Testing the stationary of the variables using the Augmented Dickey-Fuller (ADF) test. From this we can find whether the variable is $\mathrm{I}(0)$ or $\mathrm{I}(1)$, or others. If variable is not I(1), then goes to stage 3 a directly, or else goes to stage 2 . 
Stage 2: Testing for co-integration between variables using the Johansen (or others) technique. If co-integration is found, then proceed to Stage $3 \mathrm{~b}$, or else go to stage $3 \mathrm{a}$.

Stage 3a: Testing for causality from variable A to variable B (and variable B to variable A) using the Hsiao's Granger.

Stage 3b: Using 'Hsiao' on 'ECM' to test long run relation. If the estimated coefficient of the EC term is positive, then causality is re-estimated with different terms as shown in Stage 3a.

The three stages' methodologies include four methods, including ADF, Johansen test, Hsiao's Granger test and 'Hsiao' on 'ECM'.

(1) $A D F$

Here take $y_{t}$ as example, ADF test based on H0: $y_{t}$ is not $\mathrm{I}(0)$ which is given by the following equation(1). If the calculated ADF statistics are less than their critical values from Fuller's table, then the null hypothesis $\left(\mathrm{H}_{0}\right)$ is rejected and the series are stationary or integrated or I(1).

$$
\Delta y_{t}=a+b y_{t-1}+\sum_{i=1}^{\gamma} c \Delta y_{t-i}+\varepsilon_{t}
$$

Where $\Delta$ is the difference operator, $a, b, c$, are parameters to be estimated, $\varepsilon_{t}$ is white noise, $\gamma$ is selected.

\section{(2) Johansen test}

Johansen test has two test means. One is trace test and the other is max Eigen-value test.

\section{(3) Hsiao's Granger test and 'Hsiao' on 'ECM'}

Hsiao's Granger is based on Granger; the results of Granger causality are very sensitive to the selection of lag length. To deal with this problem, Hsiao (1981) has developed a systematic autoregressive method for choosing optimal lag length for each variable in an equation. This method combines Granger causality and Akaike's Final Prediction Error (FPE).

The standard Granger (1969) test states that, if past values of a variable $Y$ significantly contribute to forecast the value of another variable $X_{t+1}$ then $Y$ is said to Granger cause $X$ and vice versa. The test is based on the following regressions.

$$
\begin{gathered}
y_{t}=\alpha_{1}+\sum_{i=1}^{m} \beta_{i} y_{t-i}+\sum_{j=1}^{n} \lambda_{j} e_{t-j}+v_{t} \\
e_{t}=\alpha_{2}+\sum_{i=1}^{m} \gamma_{i} e_{t-i}+\sum_{j=1}^{n} \delta_{j} y_{t-j}+\varepsilon_{t}
\end{gathered}
$$

Where $y_{t}$ and $e_{t}$ are the variables to be tested,

$$
y_{t}=\ln \left(Y_{t}\right) ; e_{t}=\ln \left(E_{t}\right) ; Y_{t}=\text { real GDP; } E_{t}=\text { Energy consumption;. } v_{t} \text { and } \varepsilon_{t} \text { are mutually uncorrelated }
$$
white noise errors; $t$ denotes the time period, $i$ and $j$ are number of lags.

In equation(1), $e$ causes y if the current value of $y$ is predicted better by including the past values of e than by not doing so. The homologous explaining to equation (2). By according to Granger (1986), the test is valid if the variables are not co-integrated. Following the developments of co-integration, for non-stationary variables, if variable is integrated one, equations (1) and(2) should be written by first difference.

$$
\begin{aligned}
& \Delta y_{t}=\alpha_{1}+\sum_{i=1}^{m} \beta_{i} \Delta y_{t-i}+\sum_{j=1}^{n} \lambda_{j} \Delta e_{t-j}+v_{t} \\
& \Delta e_{t}=\alpha_{2}+\sum_{i=1}^{m} \gamma_{i} \mathrm{H} e_{t-i}+\sum_{j=1}^{n} \delta_{j} \Delta y_{t-j}+\varepsilon_{t}
\end{aligned}
$$

The key of Hsiao's Granger is applying Akaike (1969) Final Prediction Error (FPE) criteria in granger test. Its main function is to confirm the lag length. The lag length is decided by the sample size and economic process. Generally, it is better to select $\mathrm{m}$ as large as possible. For example, to test whether $e_{\text {causes }} y$, one-dimensional autoregressive process is first estimated as equation(5), the value of $i$ is from 1 to $\mathrm{m}$. Then we can compute the FPE for each equation (m changing), and compute the equation(6). The optimal lag length $m$ is the lag length which produces the lowest FPE. 


$$
\begin{aligned}
& \Delta y_{t}=\alpha_{1}+\sum_{i=1}^{m} \beta_{i} \Delta y_{t-i}+v_{t} \\
& \operatorname{FPE}(m)=\frac{T+m+1}{T-m-1} \operatorname{SSE}(m) / T
\end{aligned}
$$

Where $T$ is sample size and $S S E$ is sum of squared errors.

According to the above statement, Hsiao's procedure requires two steps. Also taking test whether $e_{\text {causes }} y$ as example.

The first step is according to equations (5) and(6), we can compute $m^{*}$.

The second step is that regressions are estimated with the lags on the other variable $(n)$ added sequentially in the same manner used to determine $m^{*}$. According to equation (3) and $m^{*}$, we compute FPE for each regression as equation(7).

$$
\operatorname{FPE}(m+n)=\frac{T+m^{*}+n+1}{T-m^{*}-n-1} \operatorname{SSE}(m+n) / T
$$

If $\operatorname{FPE}\left(m^{*}+n^{*}\right)<\operatorname{FPE}\left(m^{*}\right)$ then $e$ Granger causes $y$, whereas $e$ does not Granger cause $y$.

The above part explains the Hsiao method based on no co-integration. If co-integration is found, then test whether $e$ causes $y$ and $y$ causes $e$ in this framework the $E C$ term is added, construct equations (8) and (9) is as follows:

$$
\begin{aligned}
& \Delta y_{t}=\alpha_{1}+\delta_{1} E C_{t-1}+\sum_{i=1}^{m} \beta_{i} \Delta y_{t-i}+\sum_{j=1}^{n} \lambda_{j} \Delta e_{t-j}+v_{t} \\
& \Delta e_{t}=\alpha_{2}+\delta_{2} E C_{t-1}+\sum_{i=1}^{m} \gamma_{i} \mathrm{H} e_{t-i}+\sum_{j=1}^{n} \delta_{j} \Delta y_{t-j}+\varepsilon_{t}
\end{aligned}
$$

where $E C$ is the error correction term from equation (3).

\section{Empirical Results}

(1) Data

The data includes GDP and energy consumption from 1953 to 2006 . We can gather data from China statistics yearbook and the net of GDP is in hundred million RMB using the present price, consumption is in ten thousands tons criteria coal which calculated by equivalent to generate power. They can be gathered from the net of the National Bureau of Statistics and China Economic Information Network. The data list in table1.

Insert Table1 Here.

(2) Results

The results of our estimations are presented step by step. The result is computed by Eviews5.1.

\section{Test for stationary}

The results are reported in table.2. This is achieved when testing $e$ and $y$ in levels by including a constant term and a time trend in the $\mathrm{ADF}$ equation whereas when testing the first differences of $e$ and $y$, the $\mathrm{ADF}$ equation includes a constant. For both, the number of lags is determined by using the Schwarz info criteria (SIC). This table shows that the series of GDP and energy consumption are stationary in the first difference, and integrated of order I(1).

Insert Table 2 Here

\section{Test for co-integration}

From above table, the variables which have been tested for the order of integration and found to have the same order are used to estimate co-integration regression. We adopt "intercept (no trend) in CE and test" and lag interval choose $(1,1)$. Table 3 reports the results of the Johansen tests. The absolute values of the calculated test statistics for all the residuals are more than its critical value at the 5 percent level. Neither series is co-integrated.

InsertTable 3 Here

\section{Hsiao's granger causality test}

Because of no co-integrated the standard Granger test is appropriate, and then we should go to stage 3a. By following the estimations based on equations (3) to(7), we are able to reach the results of Hsiao's Granger test reported in tab.4.

Insert Table 4 Here 
The results of Hsiao's causality tests indicate that economic growth causes energy consumption and energy consumption causes economic growth respectively by the GDP equation and the energy consumption equation, where two equations have the condition of $\operatorname{FPE}\left(m^{*}+n^{*}\right)<\operatorname{FPE}\left(m^{*}\right)$.

As for economic growth causes energy consumption, the economy development is supported by heavy industry and construction industry. Two industries both are high energy consumption industries. More serious is that the price of energy is low; the consciousness of saving energy is dim. So the development of economy is in the cost of energy consumption. So the economic growth causes energy consumption.

As for energy consumption causes economic growth, the energy is one of based industries. The consumption of energy is produced in domestic in China. Sensitive factor and influential factor of energy industry both are high, so the development of energy industry drives the growth of other industry, and then promotes economic growth.

\section{Summary and Policy Implications}

In this paper we try to investigate the casual relationship between growth in energy consumption and growth in GDP, especially discussing whether uni-directional or bi-directional causality exists between energy consumption and economic growth in China. From the data analysis, we find the logarithm of GDP and economic consumption are one integrated by ADF test. From Johansen co-integration test, co-integration is not found. Then according to Hsiao's granger causality test, we can inform that economic growth granger causes energy consumption and energy consumption granger causes economic growth.

The result has important policy implications. China is a big energy consumer agent, which has a huge gap between energy supply and demand. What is more serious is that Chinese energy efficiency is very low. So the economic growth needs more energy. The economic growth was supported by construction, steel, metallurgy, equipment electro-analysis aluminum, glass and etc, all of which are high consumer of energy. In a way, this is concerned with the economic development phase. But we should also change the increase mode of economy and consciousnesses of energy consume, pay attention to saving energy and enhancing energy efficiency from the whole energy chain. In detail we should do as hereinafter.

Firstly, to enhance the rate of taxes and the price of energy, bring up the consciousness of saving energy and improve the exploitation efficiency step by step. Secondly, bring price difference of electrovalence in practice, higher price to the industries which have high level of energy consumption; promote them to enhance the energy using efficiency. Thirdly, improve on manner of economic using, especially in living. Fourthly, pay attention to circulation use of energy.

\section{References}

Altinay, G., Karagol, E. (2005). Electricity Consumption and Economic Growth: Evidence from Turkey. Energy Economics 27: 849-856.

Anjum, Aqeel, Mohammad Sabihuddin Butt. (2000). The Relationship between Energy Consumption and Economic Growth in Pakistan. Asia-Pacific Development Journal 8:101-110.

Cheng, S. Benjamin, Tin Wei Lai. (1997). An investigation of co-integration and causality between energy consumption and economic activity in Taiwan Province of China", Energy Economics 19,:435-444.

Hondroyiannis, G., Lolos, S., Papapetrou, E. (2002). Energy Consumption and Economic Growth: Assessing the Evidence from Greece. Energy Economics 24: 319-336.

Lee, C. (2005). Energy Consumption and GDP in Developing Countries: A Co-integrated Panel Analysis. Energy Economics 27: 415-427.

Mahendra Reddy. (1998). Energy consumption and economic activity in Fiji. Energy consumption and economic activity22:81-96.

Morimoto, R., Hope, C. (2004). The Impact of Electricity Supply on Economic Growth in Srilanka. Energy Economics 26: 77-85.

Oh, W., Lee, K. (2004a) .Causal Relationship between Energy Consumption and GDP Revisited: The Case of Korea 1970-1999. Energy Economics 26: 51-59.

Paul, S. (2004). Causality between Energy Consumption and Economic Growth in India: A Note on Conflict Results. Energy Economics 26: 997-983.

Shiu, A., Lam, P. L. (2004). Electricity and Economic Growth in China. Energy Policy 32: 47-54.

Wolde, Rufael. (2005). Energy Demand and Economic Growth: The African Experience. Journal of Policy Modeling 27: 891-903.

Yang, H. Y. (2000). A Note of the Causal Relationship between Energy and GDP in Taiwan. Energy Economics 22: 309-317.

Yoo, S. H. (2005). Electricity Consumption and Economic Growth: Evidence from Korea. Energy Policy 33: 
$1627-1632$

Cheng, B. S. (1998). Energy Consumption, Employment and Causality in Japan: A Multivariate Approach. Indian Economic Review 33(1): 19-29.

Cheng, B. S. (1999). Causality between Energy Consumption and Economic Growth in India: An Application of Co-integration and Error-Correction Modeling. Indian Economic Review 34(1): 39-49.

Cheng, B. S., Lai, W. L. (1997). An Investigation of Co-integration and Causality between Energy Consumption and Economic Activity in Taiwan. Energy Economics 19: 435-444.

Ghali,, El-Sakka. (2004). Energy Use and Output Growth in Canada: A Multivariate Co-integration Analysis. Energy Economics 26: 225-238.

Hsiao. (1982). Autoregressive Modeling and Causal Ordering of Economic Variables. Journal of Economic Dynamics and Control 4: 243-259.

Wolde-Rufael, Y. (2005). Energy Demand and Economic Growth: The African Experience. Journal of Policy Modeling 27: 891-903.

Yu, E. S. H., Choi, J. Y. (1985). The Causal Relationship between Energy and GNP : An International Comparison. Journal of Energy and Development 10(2): 249-272.

Yu, E. S. H., Chow, P. C. Y., Choi, J. Y. (1998). The Relationship between Energy and Employment: A Reexamination. Energy Systems and Policy 11: 287-295.

Yu, E. S. H., Jin, J. C. (1992). Co-integration Tests of Energy Consumption, Income, and Employment. Resources and Energy 14: 259-266.

Yu, E. S. H., Hwang, B. K. (1984) The Relationship between Energy and GNP, Further Results. Energy Economics 6(3): 186-190.

Jumbe, C. B. L. (2004). Co-integration and Causality between Electricity Consumption and GDP: Empirical Evidence from Malawi. Energy Economics 26: 61-68.

Glasure, Y. U. (2002). Energy and National Income in Korea: Further Evidence on the Role of Omitted Variables. Energy Economics 24: 355-365.

Aqeel, A., Butt, M. S. (2001). The Relationship between Energy Consumption and Economic Growth in Pakistan. Asia-Pacific Development Journal 8(2): 101-109.

Asafu-Adjaye, J. (2000). The Relationship between Energy Consumption, Energy Prices and Economic Growth: Time Series Evidence from Asian Developing Countries. Energy Economics 22: 615-625.

Table1. Data

\begin{tabular}{|l|l|l|l|l|l|}
\hline Year & GDP & Energy & Year & GDP & Energy \\
\hline 1953 & 824.2 & 5411 & 1980 & 4545.6 & 60275 \\
\hline 1954 & 859.4 & 6234 & 1981 & 4891.6 & 59447 \\
\hline 1955 & 910.8 & 6968 & 1982 & 5323.4 & 62067 \\
\hline 1956 & 1029 & 8800 & 1983 & 5962.7 & 66040 \\
\hline 1957 & 1069.3 & 9644 & 1984 & 7208.1 & 70904 \\
\hline 1958 & 1308.2 & 17599 & 1985 & 9016 & 76682 \\
\hline 1959 & 1440.4 & 23926 & 1986 & 10275.2 & 80850 \\
\hline 1960 & 1457.5 & 30188 & 1987 & 12058.6 & 86632 \\
\hline 1961 & 1220.9 & 20390 & 1988 & 15042.8 & 92997 \\
\hline 1962 & 1151.2 & 16540 & 1989 & 16992.3 & 96934 \\
\hline 1963 & 1236.4 & 15567 & 1990 & 18667.8 & 98703 \\
\hline 1964 & 1455.5 & 16637 & 1991 & 21781.5 & 103783 \\
\hline 1965 & 1717.2 & 18901 & 1992 & 26923.5 & 109170 \\
\hline 1966 & 1873.1 & 20269 & 1993 & 35333.9 & 115993 \\
\hline 1967 & 1780.3 & 18328 & 1994 & 48197.9 & 122737 \\
\hline 1968 & 1730.2 & 18405 & 1995 & 60793.7 & 131176 \\
\hline 1969 & 1945.8 & 22730 & 1996 & 71176.6 & 138948 \\
\hline 1970 & 2261.3 & 29291 & 1997 & 78973 & 137798 \\
\hline 1971 & 2435.3 & 34496 & 1998 & 84402.3 & 132214 \\
\hline 1972 & 2530.2 & 37273 & 1999 & 89677.1 & 133831 \\
\hline 1973 & 2733.4 & 39109 & 2000 & 99214.6 & 138553 \\
\hline 1974 & 2803.7 & 40144 & 2001 & 109655.2 & 143199 \\
\hline 1975 & 3013.1 & 45425 & 2002 & 120332.7 & 151797 \\
\hline 1976 & 2961.5 & 47831 & 2003 & 135822.8 & 174990 \\
\hline
\end{tabular}


Table 2. Unit root tests

\begin{tabular}{|l|l|l|l|l|l|l|l|}
\hline \multirow{2}{*}{ Variables } & ADF Test & ADF Test & \multirow{2}{*}{ Result } \\
\cline { 2 - 7 } & Level & P-value* & Lag & Difference & P-value & Lag & I(1) \\
\hline $\operatorname{lnGDP}$ & -1.2910 & 0.8790 & 2 & -4.0143 & 0.0028 & 1 & 1 \\
\hline $\ln$ Energy & -2.1706 & 0.4943 & 6 & -4.1669 & 0.0018 & $\mathrm{I}(1)$ \\
\hline *MacKinnon (1996) one-sided p-values.
\end{tabular}

Table 3. Co-integration tests

\begin{tabular}{|c|c|c|c|c|c|c|c|}
\hline \multicolumn{2}{|c|}{ Hypothesis } & \multicolumn{4}{|c|}{ Johansen Test statistics } & \multirow{2}{*}{$\begin{array}{l}\text { Co-integration } \\
\text { accepted? }\end{array}$} & \multirow{2}{*}{ Note } \\
\hline $\mathrm{H} 0$ & H1 & Trace & $5 \%$ & Max-eig & $5 \%$ & & \\
\hline $\mathrm{r}=0$ & $r>0$ & 10.7689 & 15.4947 & 10.6679 & 14.2646 & \multirow[b]{2}{*}{ No } & \multirow{2}{*}{$\begin{array}{l}\text { Both tests indicate no co-integrating } \\
\text { equation at } 5 \%\end{array}$} \\
\hline $\mathrm{r}<=1$ & $\mathrm{r}>1$ & 0.1010 & 3.8415 & 0.1010 & 3.8415 & & \\
\hline
\end{tabular}

Table 4. Results of Hsiao's causality tests

\begin{tabular}{|c|c|c|c|c|c|c|c|}
\hline Item & $\mathrm{F}\left(\mathrm{m}^{*}\right)$ & $\mathrm{m} *$ & $\mathrm{SSE}\left(\mathrm{m}^{*}\right)$ & $\mathrm{F}\left(\mathrm{m}^{*}, \mathrm{n}^{*}\right)$ & $\mathrm{N} *$ & $\mathrm{SSE}\left(\mathrm{m}^{*}, \mathrm{n}^{*}\right)$ & $\mathrm{Causality}$ Result \\
\hline The GDP Equation & 0.1899 & 6 & 0.1448 & 0.1745 & 1 & 0.1280 & $e \rightarrow y^{\prime}$ \\
\hline The energy consumption equation & 0.3467 & 6 & 0.2644 & 0.3249 & 1 & 0.2383 & $y \rightarrow e$ \\
\hline
\end{tabular}

